\title{
Familial aggregation of melanoma risks in a large population-based sample of melanoma cases
}

Colin B. Begg ${ }^{1, *}$, Amanda Hummer ${ }^{1}$, Urvi Mujumdar ${ }^{1}$, Bruce K. Armstrong ${ }^{2}$, Anne Kricker ${ }^{2}$, Loraine D. Marrett ${ }^{3}$, Robert C. Millikan ${ }^{4}$, Stephen B. Gruber ${ }^{5}$, Hoda Anton-Culver ${ }^{6}$, Judith B. Klotz ${ }^{7}$, Roberto Zanetti ${ }^{8}$, Richard P. Gallagher $^{9}$, Terence Dwyer ${ }^{10}$, Timothy R. Rebbeck ${ }^{11} \&$ Marianne Berwick $^{12}$

${ }^{1}$ Memorial Sloan-Kettering Cancer Center, New York, NY, USA; ${ }^{2}$ The University of Sydney, Sydney, NSW, Australia; ${ }^{3}$ Cancer Care Ontario, Toronto, Canada; ${ }^{4}$ University of North Carolina, Chapel Hill, NC, USA; ${ }^{5}$ University of Michigan, Ann Arbor, MI, USA; ${ }^{6}$ University of California at Irvine, Irvine, CA, USA; ${ }^{7}$ University of Medicine and Dentistry of New Jersey, Piscataway, NJ, USA; ${ }^{8}$ Centro per la Prevenzione Oncologia, Torino, Piemonte, Italy; ${ }^{9}$ British Columbia Cancer Agency, Vancouver, Canada; ${ }^{10}$ University of Tasmania, Hobart, Tasmania, Australia; ${ }^{11}$ University of Pennsylvania, Philadelphia, PA, USA; ${ }^{12}$ University of New Mexico, Albuquerque, NM, $U S A$

Received 30 March 2004; accepted in revised form 15 June 2004

Key words: analyses, cohort, melanoma, risk factors.

\begin{abstract}
Objective: Melanoma has been shown in numerous studies to be associated with sun exposure, and with host phenotypic factors of genetic origin. In this study we use information from a large series of incident cases of melanoma from an international population-based study to examine the patterns of incidence of melanoma in the first-degree relatives of these cases.

Methods: A total of 2508 incident cases of melanoma provided information on basic demographic data and pigmentary characteristics, in addition to detailed information on family history of melanoma. These data were used to examine the incidence rates ratios of melanoma in the relatives of cases in relation to population rates, and also with respect to phenotypic characteristics of the probands that have been shown to be associated with melanoma: mole counts, hair color, eye color, and skin sensitivity to the sun.

Results: The incidence rates reflect the underlying patterns of incidence in the source populations, with generally higher rates in the Australian sample, low rates in Italy, and intermediate rates in the USA and Canada. Also, rates are higher in men than in women, except at very young ages. Phenotypic characteristics of the probands were only weakly associated with the observed rates in the relatives although there is a strong inverse association with age at diagnosis. Cumulative risk of melanoma rises to $6.9 \%(6.1 \%)$ at age 80 in male (female) first-degree relatives of cases, and to $10.8 \%(9.5 \%)$ in relatives of cases diagnosed before age 50 .

Conclusions: Relatives of cases diagnosed with melanoma are at considerable lifetime risk of the disease, especially if the case is diagnosed at a young age.
\end{abstract}

\section{Introduction}

In 1999, a group of investigators initiated a populationbased international case-control study to examine

* Address correspondence to: Colin B. Begg, PhD, Department of Epidemiology and Biostatistics, Memorial Sloan-Kettering Cancer Center, 307 East 63rd Street, 3rd Floor, New York, NY 10021, USA; Ph.: 646-735-8108; Fax: 646-735-0009; E-mail: korvae@mskcc.org genetic risk factors for melanoma and their possible interactions with sun exposure (the Genes, Environment, and Melanoma (GEM) study). In this report we use data from this study to examine the reported incidence of melanoma in the birth cohort of firstdegree relatives of probands with a first primary diagnosis of melanoma.

This strategy provides a rich resource of information, since the incidence of melanoma in the relatives of 
subjects with melanoma is substantially higher than the population incidence of the disease. We are able to examine the pattern of incidence rates in these subjects with respect to the geographical regions from which the corresponding probands were sampled, regions with wide variations in the incidence of melanoma $[1,2]$. We are also able to estimate the cumulative risk of melanoma in relatives of cases diagnosed with the disease.

Melanoma is associated with sun exposure, the only well-established environmental risk factor [3]. In addition, numerous studies have demonstrated associations between melanoma and pigmentary characteristics that are likely to have genetic origin. Several of these, such as hair color, eye color, and propensity to freckle were examined in a meta-analysis that demonstrated significant effects for each of these factors [4]. Stronger associations have been demonstrated in many studies for total nevi counts, although no meta-analysis of this risk factor has been conducted to date. Rare mutations in CDKN2A encoding for the protein $\mathrm{p} 16$ has been shown to be a strong risk factor in melanoma families [5-7].

Data from our study offer the opportunity to examine the relationship between the presence of these factors in the melanoma cases that are the probands for our study and the incidence of melanoma in their first-degree relatives, and in this report we focus on factors reported via interview. All cancer risk factors are over-represented among incident cases, and so relatives of cases with identified risk factors of genetic origin should also have elevated risk. $[8,9]$. Our results offer insights into which subsets of the population are at sufficiently elevated risk of melanoma to be targeted for focussed cancer prevention strategies.

\section{Methods}

The GEM study involves the population-based ascertainment of incident cases of melanoma in nine geographic regions of the world: New South Wales (Australia); Tasmania (Australia); British Columbia (Canada); Ontario (Canada); Torino (Piemonte, Italy); California (Orange County and San Diego, USA); Michigan (USA); New Jersey (USA); North Carolina (USA). The present report is limited to incident cases of first primary invasive melanoma diagnosed during a 6-month period January 1, 2000-June 30, 2000 with the following exceptions: the whole of 2000 in California and North Carolina; from January 1, 2000 to August 31, 2000 in Ontario, and from June 1, 2000 to May 31, 2001 in Torino, Italy. Risk factors of interest were measured by data collected from a self-administered questionnaire, a telephone interview, and by testing DNA from buccal cells or blood. The study protocol was approved by the Coordinating Center's Institutional Review Board (at Memorial Sloan-Kettering Cancer Center in New York), and by those at each of the contributing sites.

These cases, hereafter referred to as the 'probands' for the current analysis, were identified by the relevant population-based cancer registry. Physician approval was obtained prior to subject contact. Research staff obtained informed consent and a self-administered questionnaire to obtain basic demographic data, pigmentary characteristics, and residence, occupation and vacation history. Subsequently, a telephone interview lasting approximately one hour was conducted in which detailed information was obtained on the family history of melanoma and other cancers, including non-melanoma skin cancer, in all first-degree relatives of the probands. Genuine first-degree relationships were carefully distinguished within the interview. Data obtained include the age at diagnosis of melanoma in those relatives who had experienced the disease, and the current age or age at death of all relatives. Information on hair color (as a teenager), eye color, skin color (without tanning), freckling (as a child), extent of moles on the body, and skin sensitivity of the probands was also obtained, but was not obtained for relatives. The skin sensitivity questions were phrased to ask the subject what would happen to one's skin if exposed to bright sunlight for the first time in summer for one hour in the middle of the day without protection [10]. The subject was also asked what would happen with repeated exposure to bright sunlight in summer without protection. For our analyses, we have characterized sensitivity in two dimensions: propensity to burn, defined as severe sunburn with blistering and/or peeling after one hour of unprotected sun exposure, and propensity to tan, defined as moderate or deep tan after repeated sun exposure. Probands were asked to have relatives or friends to count the number of moles on their backs. Pathology slides were obtained and were reviewed by one of three central pathologists (or by two if there was disagreement between the original diagnosis and that of the first review pathologist).

All data were collected and sent to the Coordinating Center on a routine basis and maintained in a database. Research staff at the Coordinating Center carried out data quality assurance. Data from the self-administered questionnaire and telephone interview were transferred either by machine-scannable forms or electronically. Simple univariate analysis and logical algorithms were used to check for logical inconsistencies in the data.

All data analyses involve the incidence rates of melanoma in the identified first-degree relatives (biological 
parents, full siblings, children), and these rates exclude the proband, except insofar as the analyses involve subgroups defined by characteristics of the proband. Person-years at risk of melanoma were determined for each relative up to the age at diagnosis of melanoma if there was an occurrence of the disease, or else to the current age or age at death. We report these rates stratified by age $(<30$, $30-49,50-69, \geq 70)$, as cumulative rates up to age 85 , and also standardized to a common standard population, the 2000 population of the USA, for comparability with the convention used in USA national statistics [11]. We used this in preference to a world standard, since the geographical regions contributing to the study have populations with an age structure similar to the USA. The familial relative risk (standardized incidence ratio) is the ratio of a rate obtained in this manner to the corresponding standardized rate in the population from which the probands were derived. Establishing the baseline rates presents an analytic dilemma since the calendar time period in which the melanomas occurred varied greatly among the reported events in the relatives, and since population rates of melanoma have been increasing, especially in the older age groups. Since the average year of diagnosis of melanoma reported in the relatives was in the region of 1990 we elected to use population rates for the period 1990-1994 as the benchmark for our estimates of incidence rates and cumulative risks, and in the denominators of our calculations of the familial relative risk. These rates were obtained from the population registries in each of the geographic regions contributing to the GEM study.

To examine the relationship of the incidence rates with pigmentary and other characteristics of the probands we initially compare the characteristics individually using unadjusted and age-standardized rates. To offset potential confounding we performed a Poisson regression analysis that permits simultaneous estimation of the various rate ratios [12]. In this analysis adjustment was made for residual clustering of outcomes within families, which has been demonstrated in a previous similar study of melanoma [13], by using a mixed model that includes a random effect for each family (normally distributed). These analyses were conducted using STATA statistical software [12]. To adjust our cumulative risk projections to project risk in subsets, e.g., relatives of probands under 30 years of age, we make use of the fact that the risk in the $i$ th risk category is given by $r_{i}=r \phi_{i} / \Sigma_{i=1}^{k} p_{i} \phi_{i}$, where $\phi_{2}, \ldots, \phi_{k}$ are the rate ratios relatives to the baseline category, $\phi_{1}=1$ by definition, $p_{1}, \ldots, p_{k}$ are the corresponding prevalences of the categories, and $r$ is the overall average risk, i.e., $r=\Sigma p_{i} r_{i}$.

\section{Results}

Details of the probands are provided in Table 1. A total of 2508 incident cases of first primary melanoma consented to participate in the GEM study. Of these we were able to obtain data on phenotypic characteristics on 2491 probands $(99.3 \%)$, and data on family history of melanoma and sun sensitivity characteristics on 2501 probands $(99.7 \%)$. The median age at melanoma diagnosis is 59 years (63 for men and 53 for women). As expected there is a male predominance. Virtually all of the probands are of white, European ancestry $(90 \%)$. Approximately $62 \%$ of the probands were accrued from North America, 6\% from Torino, and the remainder from Australia (32\%). Data are available on 16,216 first-degree relatives of these probands. Thirty-nine of the probands reported that they were adopted. All of the other probands, and all 39 of the adoptees, provided information on at least one known biological first-degree relative. A total of 340 cases of melanoma are reported in these relatives, 173 in 4966 parents, 131 in 6158 siblings, and 36 in 5085 children. The preponderance have been reported in

Table 1. Characteristics of probands

\begin{tabular}{ll}
\hline Number of probands: & Frequencies \\
\hline Total consented & 2508 \\
Telephone interview $^{\mathrm{a}}$ & $2501(99.7 \%)$ \\
Self-administered form $^{\mathrm{b}}$ & $2491(99.3 \%)$ \\
Both $_{\text {Ages }}{ }^{\mathrm{s}}$ & $2491(99.3 \%)$ \\
$<30$ & \\
$30-49$ & $151(6 \%)$ \\
$50-69$ & $794(32 \%)$ \\
$\geq 70$ & $1007(40 \%)$ \\
Sex & $549(22 \%)$ \\
Male & \\
Female & $1297(52 \%)$ \\
Contributing registry & \\
New South Wales & $1204(48 \%)$ \\
Tasmania & \\
British Columbia & $725(29 \%)$ \\
Ontario & $80(3 \%)$ \\
Torino & $119(5 \%)$ \\
California (Irvine) & $432(17 \%)$ \\
Michigan & $148(6 \%)$ \\
New Jersey & $218(9 \%)$ \\
North Carolina & $320(13 \%)$ \\
& $171(7 \%)$ \\
& $288(11 \%)$ \\
\hline &
\end{tabular}

${ }^{a}$ Data on family history and sun sensitivity.

${ }^{\mathrm{b}}$ Data on phenotypic characteristics.

c Restricted to analyzable cases, i.e., those with data available on family history. 
parents and siblings, as we would expect, given the relatively young age of children of probands. Due to the relatively small numbers of events, siblings and other first-degree relatives are aggregated in all subsequent presentations.

The age- and sex-specific incidence rates in the relatives are presented in Table 2, separately for Australia and North America. (The results from Italy are not included in Table 2. There were only six reported melanomas among the Italian relatives, where the population rates are much lower, and so the data are too sparse to provide reliable estimates of rates.) Consistent with the recognition that melanoma aggregates in families, the rates are substantially higher than the corresponding population rates, but they reflect the typical trends of those populations. That is, the rates in Australia are generally higher than in North America (except for elderly men and women), and the rates in women are slightly higher than in men at young ages, but lower as age increases. The degree of elevation in incidence in these relatives of cases can be characterized by the familial risk ratio (FRR), the ratio of the standardized rate in relatives to the population standardized rates. The FRR is 1.5 (1.1-1.8) in Australian males, 3.2 (2.6-3.9) in North American males, 2.0 (1.62.5) in Australian females, and 4.4 (3.5-5.2) in North American females.
Rate comparisons, grouped by phenotypic characteristics and ages of the probands, are provided in Table 3. The incidence rates are higher in relatives of probands who experienced melanoma at a young age. The rates are also elevated, though more modestly and not significantly, in relatives of probands who possess known phenotypic characteristics associated with melanoma risk, such as higher mole count, red hair, propensity to burn in the sun, and propensity to tan. Adjusted analyses using Poisson regression lead to similar conclusions.

Finally, Figure 1 illustrates how these data can be used to characterize the risks of melanoma in relatives of a patient who has been diagnosed with the disease. The figure displays the cumulative incidence in male (in black) and female (in blue) relatives of cases diagnosed in North America. The cumulative risk in a male relative rises to $0.8 \%(0.5-1.1 \%)$ by age $50,3.6 \%(2.7-4.6 \%)$ by age 70 , and $6.9 \%(5.0-8.8 \%)$ by age 80 . The corresponding cumulative risks in female relatives are $1.3 \%$ $(0.9-1.7 \%)$ by age $50,4.0 \%(3.0-4.9 \%)$ by age 70 and $6.1 \%(4.6-7.6 \%)$ by age 80 . The baseline rates for this cohort, obtained using the 1990-1994 rates reported to SEER, are $0.4 \%, 1.2 \%$ and $1.8 \%$ to ages 50,70 and 80 , respectively, in men, and $0.4 \%, 0.8 \%$ and $1.1 \%$, respectively in women. These are plotted in red and green in Figure 1.

Table 2. Incidence rates in relatives

\begin{tabular}{|c|c|c|c|c|c|c|}
\hline Region $^{a}$ & Sex & Age & $\#^{\mathrm{b}}$ & $\mathrm{PY}^{\mathrm{c}}$ & $\begin{array}{l}\text { Familial } \\
\text { Rate }^{\mathrm{d}}\end{array}$ & $\begin{array}{l}\text { Population } \\
\text { Rate }^{\mathrm{e}}\end{array}$ \\
\hline \multirow{4}{*}{ Australia } & \multirow[t]{4}{*}{ Male } & $<30$ & 4 & 77335 & $5(0-10.2)$ & 5 \\
\hline & & $30-49$ & 27 & 38305 & $70(44-97)$ & 33 \\
\hline & & $50-69$ & 29 & 20471 & $142(90-193)$ & 94 \\
\hline & & $\geq 70$ & 10 & 5232 & $191(73-310)$ & 183 \\
\hline \multirow[t]{4}{*}{ North America } & \multirow[t]{4}{*}{ Male } & $<30$ & 3 & 137733 & $2(0-4.6)$ & 2 \\
\hline & & $30-49$ & 17 & 68343 & $25(13-37)$ & 14 \\
\hline & & $50-69$ & 45 & 36095 & $125(88-161)$ & 36 \\
\hline & & $\geq 70$ & 23 & 9065 & $254(150-357)$ & 57 \\
\hline \multirow[t]{4}{*}{ Australia } & \multirow[t]{4}{*}{ Female } & $<30$ & 6 & 77034 & $8(1.6-14)$ & 7 \\
\hline & & $30-49$ & 23 & 38542 & $60(35-84)$ & 35 \\
\hline & & $50-69$ & 36 & 22049 & $163(110-217)$ & 64 \\
\hline & & $\geq 70$ & 11 & 7007 & $157(64-250)$ & 78 \\
\hline \multirow[t]{4}{*}{ North America } & \multirow[t]{4}{*}{ Female } & $<30$ & 3 & 136335 & $2(0-4.7)$ & 3 \\
\hline & & $30-49$ & 37 & 67692 & $55(37-72)$ & 15 \\
\hline & & $50-69$ & 39 & 37069 & $105(72-138)$ & 22 \\
\hline & & $\geq 70$ & 21 & 12601 & $167(95-238)$ & 24 \\
\hline
\end{tabular}

${ }^{\text {a }}$ Excludes Italian cohort due to inadequate sample size.

${ }^{\mathrm{b}}$ Number of melanomas among kin.

c Person-years follow-up.

${ }^{\mathrm{d}}$ Rate per 100,000 person years $(95 \% \mathrm{CI})$.

e Population rate per 100,000 person years for period 1990-94, obtained from weighted average of individual population rates, weighted by numbers of probands from each population in the given region. 
Table 3. Rates by phenotypic characteristics of probands

\begin{tabular}{|c|c|c|c|c|c|}
\hline Characteristic & \# & PY & $\begin{array}{l}\text { Age } / \text { Sex } \\
\text { standardized rate }\end{array}$ & $\begin{array}{l}\text { Rate ratio } \\
(95 \% \mathrm{CI})\end{array}$ & $\begin{array}{l}\text { Adjusted rate } \\
\text { ratio }^{b}(95 \% \mathrm{CI})\end{array}$ \\
\hline \multicolumn{6}{|c|}{ Age at diagnosis (proband) } \\
\hline$\geq 70$ & 68 & 251,926 & 31 & 1.0 & 1.0 \\
\hline $50-69$ & 141 & 256,392 & 55 & $1.8(1.3-2.4)$ & $1.6(1.1-2.3)$ \\
\hline $30-49$ & 117 & 201,448 & 107 & $3.4(2.7-4.4)$ & $3.1(2.1-4.6)$ \\
\hline$<30$ & 14 & 22,951 & 84 & $2.7(1.5-4.7)$ & $4.3(2.0-9.3)$ \\
\hline \multicolumn{6}{|l|}{ Mole count on back } \\
\hline$<5$ & 107 & 311,799 & 45 & 1.0 & 1.0 \\
\hline $5-10$ & 84 & 185,103 & 62 & $1.4(1.0-1.8)$ & $1.3(0.9-1.9)$ \\
\hline $11-25$ & 79 & 163,183 & 69 & $1.6(1.1-2.1)$ & $1.4(0.9-2.0)$ \\
\hline$>25$ & 63 & 145,088 & 61 & $1.4(1.0-1.9)$ & $1.2(0.8-1.8)$ \\
\hline \multicolumn{6}{|l|}{ Hair color } \\
\hline Dark brown/black & 95 & 260,665 & 48 & 1.0 & 1.0 \\
\hline Light brown/blonde & 192 & 478,705 & 54 & $1.1(0.9-1.4)$ & $1.0(0.7-1.4)$ \\
\hline Red & 41 & 68,570 & 90 & $1.9(1.3-2.6)$ & $1.5(0.9-2.5)$ \\
\hline \multicolumn{6}{|l|}{ Eye color } \\
\hline Dark & 54 & 161,202 & 46 & 1.0 & 1.0 \\
\hline Light & 278 & 653,932 & 58 & $1.3(0.9-1.7)$ & $1.1(0.8-1.9)$ \\
\hline \multicolumn{6}{|l|}{ Freckles in childhood } \\
\hline None & 123 & 337,450 & 46 & 1.0 & 1.0 \\
\hline Few & 137 & 292,224 & 68 & $1.5(1.2-1.9)$ & $1.1(0.9-1.6)$ \\
\hline Many & 52 & 98,336 & 75 & $1.6(1.2-2.2)$ & $1.0(0.7-1.8)$ \\
\hline \multicolumn{6}{|l|}{ Propensity to burn } \\
\hline No & 171 & 453,420 & 51 & 1.0 & 1.0 \\
\hline Yes & 163 & 359,815 & 64 & $1.3(1.0-1.6)$ & $1.1(0.8-1.5)$ \\
\hline \multicolumn{6}{|l|}{ Propensity to tan } \\
\hline Yes & 183 & 476,211 & 52 & 1.0 & 1.0 \\
\hline No & 152 & 336,736 & 63 & $1.2(1.0-1.5)$ & $1.2(0.9-1.6)$ \\
\hline
\end{tabular}

${ }^{a}$ Rate per 100,000 person-years, standardized by sex, and by age to the USA population, 2000.

b Adjusted for all factors listed in addition to the sex and age at diagnosis of the relative, and residual familial clustering using Poisson regression analysis

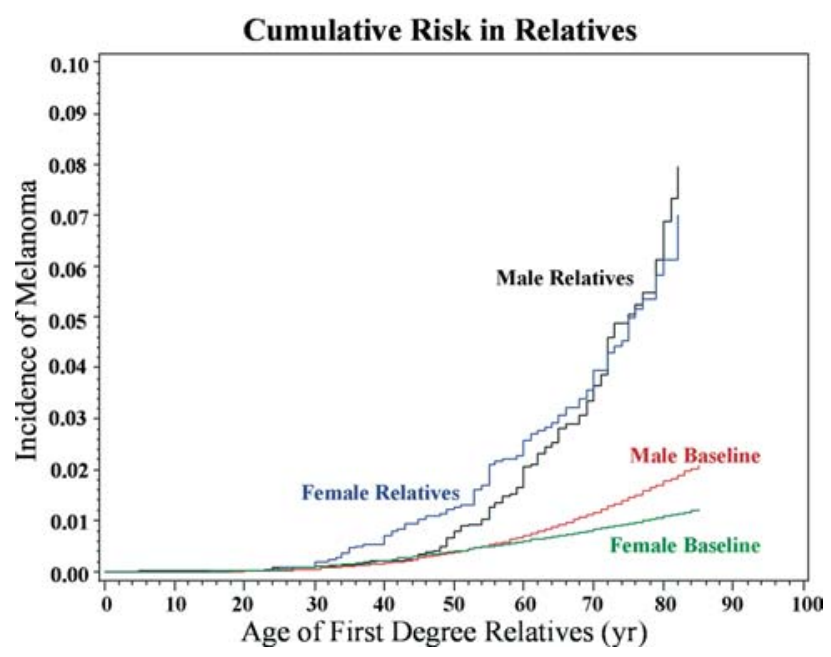

Fig. 1. The black and blue curves represent the estimated cumulative incidence of melanoma in relatives of patients diagnosed with melanoma for male and female relatives, respectively. The baseline curves are the corresponding cumulative risks of melanoma in North American men and women (adapted from SEER incidence rates, 1990-94).

\section{Discussion}

Our study provides insights into the nature of familial aggregation of melanoma. A synthesis of eight published case-control studies involving 2952 cases of melanoma and 3618 controls provided a summary estimate of the relative risk of melanoma in individuals with a 'family history' of melanoma of 2.2 (1.8-2.9), where family history was defined as the presence of one or more first degree relatives [14]. Our analysis inverts this conventional analytic strategy, by examining in detail the ageand sex-specific incidence rates in first degree relatives of melanoma cases, using relevant population rates of melanoma as the benchmark. The resulting rate ratios, or 'familial relative risks' in the terminology of Risch [15], provide measures of the degree of familial aggregation. In our study these range from 1.5 in the Australian male cohort to 4.4 in the North American female cohort. These span the results obtained in a 
recent population-based study in Sweden, where familial relative risks of 2.4 and 3.0 were observed for offspring and siblings, respectively [16]. However, in all settings they represent substantial (and statistically significant) familial aggregation. Risch has further shown that under the assumption of an additive genetic model the excess relative risk from these calculations (or more specifically the excess in siblings) should be approximately one half of the excess relative risk in identical twins, in which the relatives are genetically identical to the probands, although there are no studies of twins with sufficient data to estimate this quantity reliably. It has also been shown that the excess relative risk in identical twins should be smaller than the excess standardized incidence ratio of second primary melanoma, with the difference being explainable by the effect of environmental factors that do not aggregate in families [17]. The overall excess standardized incidence ratio of second primaries observed using SEER data is indeed, at 7.5, more than double the excess familial relative risk we have observed in this study.

Numerous previous case-control studies have demonstrated consistent associations between 'phenotypic' characteristics and melanoma risk, and so it is of interest to see if the familial aggregation is consistent with these characteristics. Because of the nature of heritability, relatives of patients with red hair, for example, will be more likely than average to have red hair, but will comprise individuals with a mixture of hair colors. Thus the excess rate ratio in relatives of patients with red hair should be attenuated. Indeed, for a single, known biallelic variant there is a predictable relationship between its relative risk (i.e. the value that would be obtained from, say, a case-control study) and the rate ratio that would be observed from studying the ratio of its occurrences in first degree relatives of carriers and non-carriers [8]. That is, the rate ratios comparing factors such as hair color of probands in relatives will be attenuated when compared with the relative risks associated with hair color in conventional case-control studies. Our results show that the phenotypic characteristics exhibit substantial attenuation of effect. Most of the observed associations are modest, and substantially smaller in magnitude than those observed in case-control studies. For example, in a meta-analysis conducted by the International Melanoma Analysis Group [4] the summary relative risks for red, light brown and blond hair compared with brown/dark hair were $2.4,1.8$ and 1.5 respectively, compared with relative risks of 1.9 (1.5, adjusted) for red hair, and 1.1 (1.0, adjusted) for light hair in Table 3. Many studies have examined the role of total nevus count or dysplastic nevi count, and these studies have also consistently demonstrated much stronger trends than exhibited in Table 3 [18-26]. The observed attenuation of some of these effects in the multivariate analysis using Poisson regression may be due in part to the fact that nevi count and other characteristics may be correlated [27, 28]. Also, it is unclear the extent to which variation in nevi count is explainable by genetic factors, or by varying exposure to the sun [29-32]. In a recent twin study the heritability of nevus density has been shown to be in the region of $65-68 \%$, with evidence of a shared environmental contribution [33, 34].

The strongest proband characteristic predicting risk in relatives is age at diagnosis, with young probands exhibiting substantially increased familial aggregation. Again this is consistent with studies of the incidence of second primary melanoma, and suggests that there is a small subset of the population with very high risk (resulting in multiple primaries in those individuals). This risk variation is likely to be fully explained only when the specific genetic variants contributing to the variation in risk are identified.

Translation of these results into cumulative risks demonstrates that the risk of melanoma in relatives of cases is substantial. For example we estimate the cumulative risk to age 80 to be $6.9 \%$ in male relatives of cases diagnosed in North America. Taking into consideration the adjusted rate ratio estimates from Table 3 , the cumulative risk to age 80 is estimated to be $10.8 \%$ in male relatives of cases diagnosed under 50 years of age, and $14.1 \%$ in male relatives of cases diagnosed at under 30 years of age. The corresponding cumulative risks to age 80 in female relatives of North American cases are $6.1 \%, 9.5 \%$ and $12.4 \%$ respectively. Furthermore, since the population incidence of melanoma has continued to rise in the past decade the current risks in relatives may be even higher than these estimates. Targeted screening of high risk individuals on the basis of having a family history of cancer has been advocated by Foon et al. [35], who identified melanoma as one of several cancers with evidence of strong familial aggregation. The Canadian Task Force on Preventive Health Care has recommended regular physical examination by a dermatologist for individuals with a first degree relative with melanoma [36]. The Australian Cancer Network/National Health and Medical Research Council has stated that firstdegree relatives of melanoma cases should be advised of the specific features that suggest melanoma, and offered surveillance [37]. Conversely, the United States Preventive Services Task Force did not find sufficient evidence to recommend for or against screening for melanoma, though their report did emphasize the fact that certain subgroups of the population are at substantially increased risk [38]. Our results help to clarify the degree of 
lifetime risk for first-degree relatives of a patient with melanoma.

Our study has some limitations. First, the information on family history of melanoma and other vital statistics in the relatives was obtained solely from proband interviews. No attempts have been made to verify diagnoses of melanoma in the relatives. The reporting of incident melanomas to cancer registries has been shown to be more incomplete than for other cancers, with only $88 \%$ reported to SEER within the mandatory 19 month reporting period [39]. However, the validity of family history data has been shown to be considerably higher for first degree than for more distant relatives, though it too varies by cancer site [40]. A study of reporting of family history of melanoma in Queensland, Australia, first with the family members in question and, if confirmed by them, then through their medical records, found lower rates of agreement [41]. Thus, uncertainty exists about both the reported familial cases and the population rates used in our denominators. Furthermore the proband was asked to give a best estimate of age at diagnosis of the relative during the interview if the exact age at diagnosis is unknown. Also, probands may have better (or worse) recollection of information about relatives with cancer than about relatives with no known cancer, for example. A second limitation is that the occurrences of cancer in the relatives took place over a range of calendar time. Although the majority occurred since 1985 , even this time period (1985-2000) is one in which secular changes in population incidence rates have been substantial. Also, these incidence trends have varied across the geographic regions of the GEM study [42, 43]. Consequently there is an element of doubt about the appropriate baseline rates to use in our estimates of familial rate ratios. Third, the phenotypic characteristics of the probands are all self-reported, and so these are subject to misclassification also. The mole count, in particular, was limited to the back, and probands were asked to have these counted by a close relative, friend, or spouse. Various studies have cast doubt on the degree of accuracy of mole counts not conducted by a dermatologist [44-46]. Good agreement, however, has been found between several trained nurse observers counting moles on the backs of children and a single observer counting them on photographs of the backs, and inter-observer agreement was greatest for counts on the backs [47]. A final limitation is the fact that we cannot adjust for sun exposure history in these analyses. Although extremely detailed sun exposure history was collected on all probands in the GEM study, no exposure data are available for the relatives. Indeed some of the observed familial aggregation may well be due to similarities of sun exposure histories within families.

In summary, the study has confirmed the strong aggregation of melanoma in families, as evidenced by the high rates of melanoma in first-degree relatives of patients with melanoma. Relatives of individuals with a diagnosis of melanoma are themselves at substantially elevated risk, especially relatives of cases with a young age at diagnosis, and they represent an important potential target for focussed cancer prevention strategies.

\section{Acknowledgements}

The study was conducted by the GEM Study Group: Coordinating Center, Memorial Sloan-Kettering Cancer Center, New York, NY, USA: Marianne Berwick (PI), Colin Begg (Co-PI), Irene Orlow (Co-Investigator), Urvi Mujumdar (Project Coordinator), Amanda Hummer (Biostatistician), Klaus Busam (Dermatopathologist), Pampa Roy (Laboratory technician), Rebecca Canchola (Laboratory technician), Yvette Monroe (Interviewer). Study Centers: The University of Sydney and the Cancer Council New South Wales, Sydney (Australia): Bruce Armstrong (PI), Anne Kricker (co-PI), Melisa Litchfield (Study Coordinator). Menzies Centre for Population Health Research, University of Tasmania, Hobart (Australia): Terence Dwyer (PI), Paul Tucker (Dermatopathologist), Nicola Stephens (Study Coordinator). British Columbia Cancer Agency, Vancouver (Canada): Richard Gallagher (PI), Teresa Switzer (Coordinator), Tim Lee (Data Manager). Cancer Care Ontario, Toronto (Canada): Loraine Marrett (PI), Elizabeth Theis (Co-Investigator), Lynn From (Dermatopathologist), Noori Chowdhuri (Coordinator), Louise Vanasse (Coordinator), Mark Purdue (Research Officer). David Northrup (Manager for CATI). Centro per la Prevenzione Oncologia Torino, Piemonte (Italy): Roberto Zanetti (PI), Stefano Rosso (Data Manager), Carlotta Sacerdote (Coordinator). University of California, Irvine (USA): Hoda Anton-Culver (PI), Nancy Leighton (Coordinator), Maureen Gildea (Data Manager). University of Michigan, Ann Arbor (USA): Stephen Gruber (PI), Joe Bonner (Data Manager). New Jersey Department of Health and Senior Services, Trenton (USA): Judith Klotz (PI), Homer Wilcox (Co-PI), Helen Weiss (Coordinator). University of North Carolina, Chapel Hill (USA): Robert Millikan (PI), Nancy Thomas (Co-Investigator), Dianne Mattingly (Coordinator), Alison Eaton (Laboratory Technician), Jessica Tse (Data Analyst). Genotyping Facilities: University of 
Pennsylvania, Philadelphia, PA (USA): Timothy Rebbeck (PI), Peter Kanetsky (Co-Investigator), Amy Walker (Laboratory Technician), Saarene Panossian (Laboratory Technician). Lawrence Livermore Laboratories, Livermore, CA (USA): Harvey Mohrenweiser (PI). Richard Setlow (Brookhaven National Laboratory, Upton, NY (USA).

Supported by the National Cancer Institute, Awards CA83180 and CA103394. Bruce Armstrong was also supported by a University of Sydney Medical Foundation Program Grant.

\section{References}

1. Armstrong BK, Kricker A (1994) Cutaneous melanoma. In: Cancer Surveys Voume 19: Trends in Cancer Incidence and Mortality. Imperial Cancer Research Fund, London.

2. Boyle P, Maisonneuve P, Dore JF (1995) Epidemiology of malignant melanoma. $\mathrm{Br}$ Med Bull 51: 523-547.

3. Elwood JM (1993) Recent developments in melanoma epidemiology, 1993. Melanoma Res 3: 149-156.

4. Bliss JM, Ford D, Swerdlow AJ, et al. (1995) Risk of cutaneous melanoma associated with pigmentation characteristics and freckling: systematic overview of 10 case-control studies. Int J Cancer 62: 367-376.

5. Kamb A, Gruis NA, Weaver-Feldhous J, et al. (1994) A cell cycle regulator potentially involved in genesis of many tumor types. Science 264: 436-440.

6. Holland EA, Beaton SC, Becker TM, et al. (1995) Analysis of the p16 gene, CDKN2, in 17 Australian kindreds. Oncogene 11: 22892294.

7. Goldstein AM, Tucker MA (2001) Genetic epidemiology of cutaneous melanoma: a global perspective. Arch Dermatol 137: 1493-1496.

8. Saunders CL, Begg CB (2003) Kin-cohort evaluation of relative risks of genetic variants. Genet Epidemiol 24: 220-229.

9. Begg CB (2002) On the use of familial aggregation in populationbased case probands for calculating penetrance. $J$ Natl Cancer Inst 94: $1221-1226$.

10. Fitzpatrick TB (1975) Soleil et peau. J Med Esthet 2: 33.

11. Ries LAG, Eisner MP, Kosary CL, et al. eds. (2002) SEER Cancer Statistics Review 1973-1999, Bethesda, MD: National Cancer Institute. Also available from: URL: http://seer.cancer.gov/csr/ 1973_1999.

12. Stata $^{\circledR}$ (2001) Reference Manual, Release 7, College Station, Texas: Stata Press.

13. Aitken JF, Duffy DL, Green A, Youl P, MacLennan R, Martin NG (1994) Heterogeneity of melanoma risk in families of melanoma patients. Am J Epidemiol 140: 961-973.

14. Ford D, Bliss JM, Swerdlow AJ, et al. (1995) Risk of cutaneous melanoma associated with a family history of the disease. Int $J$ Cancer 62: 377-381.

15. Risch N (1990) Linkage strategies for genetically complex traits: I. multilocus models. Am J Hum Genet 46: 222-228.

16. Hemminki K, Zhang H, Czene K (2003) Familial and attributable risks in cutaneous melanoma: effects of proband and age. I Invest Dermatol 120: 217-223.

17. Begg CB (2001) The search for cancer risk factors: when can we stop looking? Am J Public Health 91: 360-364.
18. Swerdlow AJ, Green A (1987) Melanocytic naevi and melanoma: an epidemiologic perspective. Br J Dermatol 117: 137-146.

19. Swerdlow AJ, English J, Mackie RM, et al. (1986) Benign melanocytic naevi as a risk factor for melanoma. $\mathrm{Br} \mathrm{Med} J \mathbf{2 9 2}$ : 1555-1559.

20. Holly EA, Kelly SW, Shpall SN, Chiu SH (1987) Number of melanocytic nevi as a major risk factor for malignant melanoma. J Am Acad Dermatol 17: 459-468.

21. Roush GC, Norlund JJ, Forget B, Gruber SB, Kirkwood JM (1988) Independence of dysplastic nevi from total nevi in determining risk for non-familial melanoma. Prev Med 17: 273-279.

22. Grob JJ, Gouvernet J, Aymar D, et al. (1990) Count of benign melanocytic nevi as a major indicator of risk for non-familial nodular and superficial spreading melanoma. Cancer 66: 387-395.

23. Augustsson A, Stierner U, Rosdahl I, Suurkula M (1990) Common and dysplastic naevi as risk factors for cutaneous malignant melanoma in Swedish population. Acta Derm Verereol 71: 518-524.

24. Kruger S, Garke C, Buttner P, Stadler R, Guggenmoos-Holzmann I, Orfaros C (1992) Epidemiologic evidence for the role of melanocytic nevi as risk markers and direct precursors of cutaneous malignant melanoma. J Am Acad Dermatol 26: 920-926.

25. Bataille V, Newton Bishop JA, Sasieni P, et al. (1996) Risk of cutaneous melanoma in relation to the numbers, types and sitzes of naevi: a case-control study. $B r J$ Cancer 73: 1605-1611.

26. Tucker MA, Halpern A, Holly EA, et al. (1997) Clinically recognized dysplastic nevi: a central risk factor for cutaneous melanoma. JAMA 277: 1439-1444.

27. Brogelli L, DeGiorgi V, Bini F, Giannotti B (1991) Melanocytic naevi: clinical features and correlation with the phenotype in healthy young males in Italy. Br J Dermatol 125: 349-352.

28. Dennis L, White E, Lee JAH, Kristal A, McKnight B, Odland P (1996) Constitutional factors and sun exposure in relation to nevi: a population-based cross-sectional study. Am J Epidemiol 143: $248-256$.

29. Dennis LK, White E, McKnight B, Kristal A, Lee JAH, Odland P (1996) Nevi and migration within the United States and Canada: a population-based cross-sectional study. Cancer Causes Control 7: $464-473$.

30. Carli P, Naldi L, Lovati S, LaVecchia C (1996) The density of melanocytic nevi correlates with constitutional variables and history of sunburns: a prevalence study among Italian schoolchildren. Int J Cancer 101: 375-379.

31. Dulon M, Weichenthal M, Blettner M, et al. (2002) Sun exposure and number of nevi in 5- to 6-year old European children. J Clin Epidemiol 55: 1075-1081.

32. Wiecker TS, Luther H, Buettner P, Bauer J, Garbe C (2003) Moderate sun exposure and nevus counts in parents are associated with development of melanocytic nevi in childhood. Cancer 97: 628-638.

33. Wachsmuth RC, Gaut RM, Barrett JH, et al. (2001) Heritability and gene-environment interactions for melanocytic nevus density examined in a UK adolescent twin study. J Invest Dermatol 117: 348-352.

34. Zhu G, Duffy DL, Eldridge A, et al. (1999) A major quantitativetrait locus for mole density is linked to the familial melanoma gene CDKN2A: a maximum-likelihood combined linkage and association analysis in twins and their sibs. Am J Hum Genet $\mathbf{6 5}$ : 483-492.

35. Foon PW, Scheuner MT, Paterson-Oshlke KL, Gwinn M, Faucett A, Khoury MJ (2002) Can family history be used as a tool for public health and preventive medicine? Genet Med 4: 304-320. 
36. Feightner JW (1994) Prevention of skin cancer. In: Canadian Task Force on Periodic Health Examination. Canadian Guide to Clinical Preventive Health Care. Ottawa: Health Canada, pp. 850-859.

37. http://www.health.gov.au/nhmrc/publications/pdf/cp68.pdf

38. US Preventive Services Task Force (2001) Screening for skin cancer: recommendations and rationale. Am J Prev Med 20: 44-46.

39. Clegg LX, Feuer EJ, Midthune DN, Fay MP, Hankey BJ (2002) Impact of reporting delay and reporting error on cancer incidence rates and trends. J Natl Cancer Inst 94: 1537-1545.

40. Ziogas A, Anton-Culver H (2003) Validation of family history data in cancer family registries. Am J Prev Med 24: 190-198.

41. Aitken JF, Youl P, Green A, MacLennan R, Martin NG (1996) Accuracy of case-reported family history of melanoma in Queensland, Australia. Melanoma Res 6: 313-317.

42. Marrett LD, Nguyen HL, Armstrong BK (2001) Trends in the incidence of cutaneous malignant melanoma in New South Wales, 1983-1996. Int J Cancer 92: 457-462.
43. Gaudette LA, Gao RN (1998) Changing trends in melanoma incidence and mortality. Health Rep 10: 29-41.

44. Buettner PG, Garbe C (2000) Agreement between self-assessment of melanocytic nevi by patients and dermatologic examination. $\mathrm{Am}$ J Epidemiol 151: 72-77.

45. Harrison SL, Buettner PG, MacLemmon R, Kelly JW, Rivers JK (2002) How good are parents at assessing melanocytic nevi on their children? A study comparing parental counts, dermatologist counts, and counts obtained from photographs. Am J Epidemiol 155: $1128-1136$.

46. Bain C, Colditz GA, Willett WC, et al. (1998) Self-reports of mole counts and cutaneous malignant melanoma in women: methodological issues and risk of disease. Am J Epidemiol 127: 703-712.

47. English DR, Armstrong BK (1994) Melanocytic nevi in children. II. Observer variation in counting nevi. Am J Epidemiol 139: 402-407. 